\title{
Communication factors impacting on the ability of a family to adjust to caring for a family member following a catastrophic injury in Western Australia
}

\author{
Caroline E Bulsara ${ }^{*}$, Beatriz Cuesta Briand ${ }^{2}$, Anne McKenzie ${ }^{2}$ and Rachael Moorin ${ }^{3}$ \\ ${ }^{1}$ The Institute for Health Research, University of Notre Dame Australia, Western Australia \\ ${ }^{2}$ School of Population Health, University of Western Australia, Perth, Western Australia \\ ${ }^{3}$ Curtin Health Innovation Research Institute, Curtin University, Western Australia, Perth, Western Australia
}

\begin{abstract}
Objectives: The study identified the issues for families affected by catastrophic injury in the early days post injury with a view to highlighting the need for some key changes to the system in Western Australia.

Methods: The research used a community participatory research framework to conduct the study. Overall, twenty-three carers of those with a catastrophic injury were interviewed using semi-structured interviewing technique. Transcripts were analysed using an iterative thematic analysis framework.

Results: The lack of preparedness for families in adapting to a family member with a permanent injury was highlighted. Experiences during the early days following the event had a major impact upon the family's ability to adjust post injury.

Conclusion: A structured pathway is needed to allow families, especially those with children, to adjust to life after the event. Families who are not financially compensable are particularly vulnerable with inadequate support in adjusting to life with a family member following a traumatic catastrophic injury.

Practice implications: Changes to the system are recommended across a number of core areas to ensure equity of access for all of those with long term catastrophic injury.
\end{abstract}

\section{Introduction}

There has been a rapid rise in Australia between 2004-2009 of the number of persons with a disability utilising rehabilitation services across the five domains of community, accommodation, community access, respite, and employment in the disability sector [1]. In addition, $40 \%$ of those requesting community services also reported having an informal or family carer [1] to assist them with the activities of daily living. In terms of a catastrophically injured person, it is now generally accepted by health professionals, the legal system and the community that the most appropriate model of care required, particularly those of a young age, to achieve their optimum recovery (functional, emotional and social) is that of structured supported care in a community environment $[2,3]$. The demand for community based rehabilitation services reflects the current trend that institutional care is no longer considered the most appropriate form for the normalization of a person post injury regardless of whether the individual is eligible for financial compensation following the event or not. Although, there are a number of resources across the whole of Australia to provide greater access to community rehabilitation and recovery programs for persons with an acquired brain injury and/or spinal chord injury [1] there is a large proportion of care that still is dependent on a family member as primary carer.

A report from this study [4] focused on the status of families affected by catastrophic injury in Western Australia and showed that support and education for carers of those who return to the community is lacking in structure and consistency with no clearly defined pathways to ensure longer term recovery strategies are in place. Although the implementation of recovery strategies is commendable, the negative impact on families who face assisting the long-term support and care of injured persons as their primary carers in the community setting cannot be understated [5]. Consequences include altered relationships and physical and emotional challenges for care recipients and their carers alike [6,7]. There is a significant body of research around the overall negative impacts for primary (unpaid) carers in terms of both the psychological and physiological stressors when caring for someone over a longer time period [8-10]. Negative impacts include a loss of income, social isolation, physical and emotional exhaustion and grief around losing the original relationship with a former partner, companion and/or family member $[9,11,12]$. In the case of catastrophic injury, the impact is sudden and due to the understandable focus

Correspondence to: Caroline E Bulsara, Research Coordinator, School of Nursing and Midwifery \& Institute for Health Research, University of Noter Dame, Western Australia, Tel: 61894330217; Email: caroline.bulsara@nd.edu.au

Key words: catastrophic injury, communication factors, family carer

Received: November 04, 2016; Accepted: December 02, 2016; Published: December 05, 2016 
around the survival of the person who has sustained the injury in the short term, the effect on the family is often poorly dealt with in both the acute care setting and during the early rehabilitation period $[13,14]$.

The overall aim of the study was to explore the experiences of families for whom a member has sustained a catastrophic injury during their post injury journey in Western Australia. As a major factor in long term adjustment, this paper focuses specifically on the sudden initial impact on the family unit during the early critical care days post injury.

\section{Methods}

\section{Methodology}

The study used a community participatory research framework $[15,16]$ given that the issues were to be explored from a consumer perspective. Since consumer and community participation from the outset was essential to the success of this project, a steering panel was convened with responsibility for all aspects of the project including the design, appropriate data collection techniques, analysis and interpretation of results along with the dissemination of results to relevant stakeholders within the community. The panel member areas of expertise were diverse and included organizational representatives from government and non-governmental organizations providing services to both clients and also family carers in the areas of acquired brain injury, paraplegia and quadriplegia. A number of panel members were also those who had sustained an injury along with two panel members who are family (informal) carers.

\section{Definition}

Catastrophic injury is defined as any traumatic injury resulting in the need for long-term attended care for activities of daily living, including brain injury, spinal chord injury causing paralysis and lower or upper limb amputation [17]. A primary caregiver is defined as a person who gives ongoing care on a day to day basis for the person with the disability without being paid a salary for the activities and support that they provide [18].

\section{Sample}

Caregiver participants for the study were recruited from rural and metropolitan areas of WA. Participants were recruited through the steering panel and community organizations who provide support specifically for those affected by catastrophic injury. The study was also advertised to potential participants via advertising in bulletins, newsletters and organizational websites commonly available to the target groups in this study. Potential participants were asked to self-identify by contacting the researcher and expressing interest in becoming involved in the study. Subsequently, a letter including consent forms and information sheets was mailed out to the potential participants. A suitable time for the interview to take place was then finalized.

\section{Data collection methods}

Key areas and issues for discussion for in-depth interviews were identified through two facilitated workshops held at the university with the steering panel. Using a standard Delphi panel process [19], drafts were distributed and re-distributed to the panel until a final set of areas for exploration during the interviews was finalized and agreed upon. Due to the sensitive nature of the study, and given the nature of the injuries sustained by potential participants, the principles of community consultation, flexibility and sensitivity always informed the development of the data collection process, ensuring that any potential risk of psychological harm or discomfort to participants was kept to a minimum.

Data were collected through a series of semi-structured interviews conducted at the participants' convenience. A total of 23 interviews were completed with persons who had taken on a role as a primary carer and were self-identified as being either a spouse or other family member. Interviews were conducted face-to-face or by telephone as preferred by the participant. Demographics of carer participants are shown in Table 1.

The data collection methods used a phenomenological approach by conducting in-depth semi structured interviews with primary carers. Phenomenology is defined by Morse \& Field [20] as seeking to gain what is the essence and core meaning of participants' experiences. A phenomenological approach was considered by the steering panel to best identify the complexity of issues amongst informants in exploring the impact of caring for someone with catastrophic injury (typically family members and/or friends) and in accessing services and support.

\section{Analysis of data}

Interviews were analyzed using an iterative thematic analysis process. Initially, transcripts were read through and analyzed manually with codes and categories being established. Both manual and computer assisted (QSR NVivo 8.0) (Bazeley P) [21] methods of data management and analysis were performed to prevent the researchers from becoming distanced from the data during the analysis process. Saturation point was achieved in terms of establishing common themes from the interviews. Numerous themes were identified as common to all twenty-three informants in regard to the issues for the family unit around caring for someone with a catastrophic injury.

\section{Ethics}

Approval for the study was provided by the University of Australia Human Ethics Committee.

\section{Results}

Overall, the largest impacts for carers included a number of key areas specifically around communication and lack of guidance during the early post injury days as shown in Table 2 .

\section{Communication}

Lack of information post injury: Carers in this study highlighted that the loss of control and sense of helplessness in the early days post injury. A number of carers felt largely excluded from the process of treatment and care for the injured family member. One immense difficulty for families lay in learning to navigate their way around the health system and simultaneously coming to terms with such a catastrophic event. One carer described this phase as 'almost drowning' in trying to cope with clinicians, organizations, accessing services and knowing what services one is entitled to through the

Table 1. Carer demographics.

\begin{tabular}{|l|c|c|c|c|}
\hline & Gender & Mean Age (yrs) & Rural & Metro \\
\hline Male & 5 & 66 yrs & 1 & 4 \\
\hline Female & 18 & 62 yrs & 4 & 14 \\
\hline Total & 23 & (overall) 63 yrs & 5 & 18 \\
\hline \multicolumn{5}{|l|}{} \\
\hline $\begin{array}{l}\text { Relationship } \\
\text { (to person with disability) }\end{array}$ & Parent & Spouse & Sibling & \\
\cline { 2 - 5 } & 15 & 6 & 2 & \\
\hline
\end{tabular}


Table 2. Key aspects post injury leading to disintegration of support networks.

\begin{tabular}{|c|c|c|}
\hline Communication & Lack of a clear pathway to recovery/guidance & Communication and guidance \\
\hline $\begin{array}{l}\text { - Initial lack of information } \\
\text { Lack of reassurance due to the fragile status of } \\
\text { the patient following the event. } \\
\text { - } \quad \text { Unfamiliarity with medical terminology } \\
\text { - The often perceived 'influence' from the health } \\
\text { care team to have the person institutionalised. }\end{array}$ & $\begin{array}{l}\text { Family sense of helplessness and relinquishing } \\
\text { of family roles to health care team } \\
\text { Diminishing role as advocate for family } \\
\text { member. } \\
\text { Lack of awareness of the impact for children } \\
\text { and younger family members of the persons } \\
\text { who sustained the injury. }\end{array}$ & $\begin{array}{l}\text { Lack of planned discharge strategies for person } \\
\text { back into the community - particularly for those } \\
\text { who are unlikely to receive compensation or } \\
\text { those living rurally. } \\
\text { No perceived intermediary for family prior to } \\
\text { discharge. } \\
\text { Social worker knowledge variable in specific } \\
\text { area post injury. }\end{array}$ \\
\hline
\end{tabular}

post injury system. The prognosis was sometimes given to the family without full explanation. Many spoke of a sense of disempowerment in the face of hospital medical professionals. The worst-case scenario was usually presented to the family by the clinician who then had to process the news and learn how to cope with the prognosis. Other participants highlighted the difficulties experienced from not knowing whether the person would live or die and that doctors in particular were unable to provide a clear prognosis for patients.

\section{Carers said}

"While he was at hospital they were quite helpful, but they were very blunt to the point. I remember this neurosurgeon called us for a meeting and he just said, 'Look, your son has had massive, massive bleeds. His brain is peppered with bleeds. Your son will never ever be anything.' And, you know, there is not lot of compassion." [Female carer 60 yrs-son with $A B I]$

"A young intern at the hospital said to me, and I was in total shock because I was with her when she got knocked down, he said, 'She'd either die tonight or otherwise she will be a vegetable.' It was just awful." [Female carer 55 yrs-sister with ABI]

Others felt too overwhelmed to ask questions in the early days and highlighted their inability to 'think straight' regarding future plans. Yet others worked on piecing together information and observation from hospital staff to draw their own conclusions.

"Well that was all the information I got, and I pretty well guessed a lot of it. I knew he was paralysed, but I didn't know the extent of the internal injuries." [Female 57 yrs-caring for son with ABI and spinal chord injuries]

Lack of reassurance: The events that occur in the early days frequently had a longer term impact on the carers participating in this study. Decision around medical care such as switching off life support machines became longer term unresolved issues amongst family members. This carer felt that the lack of information from medical staff had led to her being made a scapegoat within the family for insisting that her husband (their father) would 'never be the same again'.

She said,

"As far as I am concerned I should never have been the bearer of bad news and had to facilitate that.

"Recently his [the injured person] brother has been really funny with me. But when I talked to him, he thought that I had actually stopped them from turning off the life support." [Female 46 yrs-caring for husband with $A B I]$

Problems were highlighted particularly for families of those sustaining a brain injury. This was attributed to the uncertainty of prognosis for those having sustained such an injury and that health professionals were reluctant to give families 'false hope' in the early months following the injury. Nonetheless, the necessity for all those involved in the person's care to explain carefully each stage of the patient's journey to family members was a foremost priority for participants in this study.

Unfamiliarity with medical terminology: Use of medical terminology by the healthcare team meant that sometimes families did not initially understand the full extent of injuries. One family carer asked her brother (a doctor) to explain her son's diagnosis because she was not given the option of a longer consultation with the hospital team following the stabilization of her son post injury. Another carer described her recollection of her relationship with the doctors at the hospital as 'very cold'. Language in describing prognosis appeared very clinical and callous to some carers with expressions such as in a vegetative state' and 'he will always be a vegetable' being noted as highly inappropriate and de-humanizing. One carer commented, '...there has got to be a better way of describing it than that.'

Perceived influence regarding institutionalization from the health care team: Some carers highlighted the perceived pressure during early days to agree to have the person placed in institutional care (nursing home). One carer participant was told that she might as well 'go home and forget about him'. Another felt because of the different areas of specialization involved during the hospitalization phase, doctors sometimes treated their 'area' but 'did not see the whole person' and future potential. Reflecting back on the early days, some carers recounted the negative advice and information they were given. In fact, 'proving medical professionals wrong' was a common theme amongst carers who participated in this study when reflecting back to the early days post injury. For example,

"They told me that he will never work, he will never do this or that. But no, with a frame, he was able to help himself." [Female carerhusband with $A B I]$

Another was told to 'go find a nursing home'. This situation was made even more stressful for those residing in Australian rural and remote locations having to decide whether to farewell the person and hand them over to institutional care in metropolitan Perth. Carers who decided against health professional advice and brought the person home spoke of the lack of support from the medical teams at the hospital ("You couldn't possibly look after him. He is such a big man"). One said that the nurse wished her 'good luck' when she said she was going to take her husband home and another said that the only option the family were offered was permanent care in a frail aged facility. The pressure of uncertainty amongst carers who decided to 'take the person home' was felt for many years after the initial days during hospitalization.

\section{Lack of clear pathway or guidance for recovery}

Disempowerment during decision making processes: Participants noted that in many cases families were presented with few options 
regarding the person's recovery. The trauma of the event followed by decisions largely made by hospital personnel without fully consulting the family were spoken of frequently by study participants. Carers and other family members already going through trauma of post injury adjustment were often not aware of the reasons behind a number of decisions made by the health team. Another explained that she had been very specifically told that her son would be institutionalized or another quite categorically told that the person 'could not go home'. Another said that the doctor only ever discussed putting her husband in an aged care facility. She said,

"And after he was interviewed, the doctor said to me, 'No, it is not worth to send him [to rehabilitation].' I said, 'What am I going to do?' They said to me, 'Put him in home.' I said, 'He has already got a home, he is coming home with me.'[Female-caring for husband with ABI and spinal chord injuries]

Diminishing role as advocate for person with injury: Language used by medical staff included words like, 'have to' and 'no choice'. One carer said, 'They always say, 'You have to'." In addition, carers noted that they would sense or perceive that an aspect of the person's care was not satisfactory but felt powerless to act. Even persisting in asking questions became problematic,

"I was taken aside and told that we cannot guarantee your husband's care if you continue to harass our staff. I was told not to look at charts, what medications he was taking and so on". [Female 46 yrs-caring for husband with $A B I]$

Lack of awareness amongst family of long term impact: Confronting the reality of a person's injuries was extremely difficult for families in the early days and some of the carers who participated reflected back on decisions to keep the person alive at the time.

"Maybe then we would have said, 'Look, just don't do it. I know that their job is to preserve life, but I mean, what are you preserving? [Son], all he does is open his eyes and breathe. I mean, he has got no life." [Female 60 yrs-caring for son with ABI]

"I didn't really know what the outcome would be. They said that he was critical; he could have gone at any time. They didn't really say that he would be like this for the rest of his life."[Female 52 yrs caring for son with $A B I$ and spinal injuries]

\section{Communication and guidance}

Lack of planned discharge and family intermediary strategies: The foremost issue resulting from this study was the significant and ongoing impact on carers' lives which is brought about by the perceived lack of involvement of families in the early days of hospitalization. In terms of family support following a catastrophic injury, one carer said that this should be initiated right back in hospital following the initial event. Families are in shock and creating a supportive atmosphere is crucial to ensuring that the family members are able to support each other over coming months and years. She explained,

"The hospital is where I actually feel that they should start with families advocating for empowering people to be involved. That is where the education and support should start. I think that is where a lot of the trauma came in. No one sat and said, look we need to sit with you and bring the family in. And that's the problem. My [husband's name] been isolated from his family. You lost control." [Female carer-Husband with $A B I$ and spinal chord injuries]

One suggestion was to provide a short handbook following the injury to explain exactly what the injury is, medical terminology and what the family can expect. This was perceived as perhaps being less confronting in the early days for some families. This carer further suggested a role for a trained facilitator or mediator at the hospital to help families work through issues, early on in the process. She further highlighted the issue with family members who are unable to realize the severity of the situation and she felt that that this would be better explained by a person external to the family instead of a parent or spouse/partner.

The intermediary role of the social worker in the hospitals: Although some participants received relevant and useful advice from a social worker whilst still in the hospital, the timing and relevance of the information was variable. Some participants said that they did not see a social worker 'for weeks' after the injured person was admitted. One said, she didn't see a social worker, 'for days and days' and another carer whose son would not be eligible for financial compensation said that it was only after five weeks that they were referred to a social worker to examine their finances regarding discharging the patient into their care. One carer said that they had frequent disagreements with the social worker regarding their son's care. However, for others, seeing a social worker in the early days provided clear benefit in planning for the longer term.

"She was really good and helped us struggle with things that were happening in there, because a lot of horrible things happened in the hospital." [Female 58 yrs-caring for son with ABI]

Some social workers were greatly valued by carers in the vulnerable early days of post injury. One said that the social worker had provided a much needed positivity in the face of an overwhelming outcome.

"And the social worker actually was with me, and she just kept saying to me on the way back, 'Look, just try and listen, try and take it in, but if you can't, it doesn't matter. But always remember the doctors are not God. And she said, believe me, he is a young healthy boy, he's never had traces of alcohol or drugs. If he is young and healthy, I have seen miracles, just remember that."' [Female 61 yrs-caring for son with ABI]

However, overall social workers were valued for helping families to access services or know what their entitlements were. One carer felt that although the social worker was available, that he/she should be more focused on children and families needing support during a vulnerable time following the accident.

\section{Discussion and implications}

\section{Discussion}

The findings demonstrate the limitations in assisting families to come to terms with resultant life changing circumstances and show the ways in which this can potentially have detrimental effects in the longer term for both the person who sustained the injury and their immediate family.

Families of the person who has sustained the catastrophic injury face some difficult and emotionally charged situations during the initial weeks post injury. During the early days in a hospital acute setting families are often overwhelmed by shock and uncertainty, initially as to whether the person would survive and then in assessing the effects on the family of either partial or complete recovery [22]. Given that the 
focus is understandably on the person who has sustained the injury, it is frequently the case that the rest of the family are left to fend for themselves in terms of coming to terms with the event and dealing with the post-traumatic stress thereof. Particularly when children are involved, this study showed that the spouse is focused on processing the event to the detriment of helping their children cope with the adjustment. This is in accord with the literature that shows that children of parents who have sustained a catastrophic injury and in particular a brain injury struggle to come to terms with the after effects of the event [23-25]. Social workers often are called upon to assist families in dealing with their grief and adjustment. However, the relevance of the information depends upon the expertise of the social worker in the area and the amount and relevance of information that the social worker may have received from the health professionals and clinicians within the hospital setting. Decisions that are made hurriedly, can often impact on the family for many years after the event and it is crucial that the health care team involve the family in all decisions regarding the wellbeing of the person who has sustained the injury. This is also seldom an instant recovery process and will require months of assisted counseling and or family meetings to process and adjust to. However, once outside of the hospital setting, families are often not monitored and the coping mechanisms of children impacted on are seldom assessed. In addition to this, the study results revealed the potential for family conflict in the wake of a spouse having the make decisions without family consultation in a facilitated setting about future care for the person with the injury [26].

\section{Implications}

The involvement in families from the early rehabilitation days ensures better coping skills for caregivers and other family members (particularly children) once the persons returns to the community once more [27]. It is vital for medical staff to realize the impact of such decisions on families and to provide clear and straightforward information to the family members in a consistent way. This study focused on the impact for families during the early days of hospitalization following a catastrophic injury. Although the short term impact of providing more intensive psychological assistance and guidance for families may be costly for the tertiary sector, in the longer term it enables families to adjust and cope longer term in living with a person with a catastrophic injury and subsequent disability.

\section{Acknowledgements}

This study was funded by the Insurance Commission of Western Australia. The researchers would also like to acknowledge and thank the steering panel members and also families and carers who gave their precious time to the project.

I confirm that all patient and personal identifiers have been disguised so that the persons described are not identifiable and cannot be identified through the details of the story.

\section{Declaration of interest}

The authors report no declaration of interest.

\section{References}

1. Australian Institute of Health and Welfare (2011) Disability support services 200809: Report on services provided under the Commonwealth State/Territory Disability Agreement and the National Disability Agreement. Disability series. Cat. no. DIS 58. Canberra: AIHW.
2. Jacobs HE, Blatnick M, Sandhorst JV (1990) What is lifelong living, and how does it relate to quality of life? $J$ Head Trauma Rehabil 5: 1-8.

3. Allen SM, Ciambrone D (2003) Community care for people with disability: blurring boundaries between formal and informal caregivers. Qual Health Res 13: 207-26.

4. Bulsara CE, Cuesta Briand B, Moorin R, McKenzie A (2010) Evaluating costs, accessibility and availability of services for those with catastrophic injury in Western Australia. Australian Centre for Economic Research \& the Centre for Health Services Research, The University of Western Australia, Perth, Western Australia. ISBN 9781-74052-202-1.

5. Douglas JM, Spellacy FJ (2000) Correlates of depression in adults with severe traumatic brain injury and their carers. Brain Inj 14: 71-88. [Crossref]

6. Anderson MI, Parmenter TR, Mok M (2002) The relationship between neurobehavioural problems of severe traumatic brain injury (TBI), family functioning and the psychological well-being of the spouse/caregiver: path model analysis. Brain Injury 16: 743-57. [Crossref]

7. Chou YC, Pu CY, Lee YC, Lin LC, Kroger T (2009) Effect of perceived stigmatization on the quality of life among ageing female family carers: a comparison of carers of adults with intellectual disability and carers of adults with mental illness. $J$ Intellect Disabil Res 53: 654-64. [Crossref]

8. Broe GA, Jorm AF, Creasey H, Casey B, Bennett H, et al. (1999) Carer distress in the general population: results from the Sydney Older Persons Study. Age Ageing 28: 307-11. [Crossref]

9. Edwards B, Higgins DJ (2009) Is caring a health hazard? The mental health and vitality of carers of a person with a disability in Australia. Med J Aust 190: S61-S65. [Crossref]

10. Davis LC, Sander AM, Struchen MA, Sherer M, Nakase-Richardson R, et al. (2009) Medical and psychosocial predictors of caregiver distress and perceived burden following traumatic brain injury. J Head Trauma Rehabil 24: 145-54. [Crossref]

11. Ergh TC, Rapport LJ, Coleman RD, Hanks RA (2002) Predictors of caregiver and family functioning following traumatic brain injury: social support moderates caregiver distress. J Head Trauma Rehabil 17: 155-172. [Crossref]

12. Chan J (2007) Carers' perspective on respite for persons with acquired brain injury. Int $J$ Rehabil Res 30: 137-146. [Crossref]

13. Rabenstein AA (2009) Ethical dilemmas in the neurologic ICU: withdrawing lifesupport measures after devastating brain injury. Continuum 15: 13-25.

14. Gan C, Gargaro J, Brandys C, Gerber G, Boschen K (2010) Family caregivers' support needs after brain injury: a synthesis of perspectives from caregivers, programs, and researchers. NeuroRehabilitation 27: 5-18. [Crossref]

15. Israel BA, Schulz AJ, Parker EA, Becker AB, Allen AJ, et al. (2008) Critical issues in developing and following CBPR principles. In Minkler M and Wallerstein, eds. Community based participatory research for health: from process to outcomes. John Wiley \& Sons. San Francisco, CA.

16. Stokols D (2006) Toward a science of transdisciplinary action research. Am J Community Psychol 38: 63-77. [Crossref]

17. Insurance Commission WA (2007) Executive Summary Annual Report 2007

18. Eagar K, Owen A, Williams K, Westera A, Marosszeky N, et al. (2007) Effective Caring: a synthesis of the international evidence on carer needs and interventions. Centre for Health Service Development, University of Wollongong.

19. Sarantakos S (1993) Social Research. Melbourne: MacMillan Education.

20. Morse J and Field PA (1995) Qualitative research methods for health professionals Thousand Oaks, CA: Sage.

21. Bazeley P (2007) Qualitative data analysis with NVivo. London: Sage.

22. Keenan A, Joseph L (2010) The needs of family members of severe traumatic brain injured patients during critical and acute care: a qualitative study. Can J Neurosci Nurs 32: 25-35. [Crossref]

23. Butera-Prinzi F, Charles N, Heine K, Rutherford B, Lattin D (2010) Family-to-Family Link Up Program: a community-based initiative supporting families caring for someone with an acquired brain injury. Neuro Rehabilitation 27: 31-47. [Crossref]

24. Hall KM, Karzmark P, Stevens M, Englander J, O'Hare P, et al. (1994) Family stressors in traumatic brain injury: a two-year follow-up. Arch Phys Med Rehabil 75: 876-884. [Crossref]

25. Yeates K, Taylor H, Walz G, Stancin T, Wade SL (2010) The family environment as a moderator of psychosocial outcomes following traumatic brain injury in young children. Neuropsychology 24: 345-56. 
Bulsara CE (2016) Communication factors impacting on the ability of a family to adjust to caring for a family member following a catastrophic injury in Western Australia

26. Evans RL, Bishop DS, Ousley RT (1992) Providing care to persons with physical disability. Effect on family caregivers. Am J Phys Med Rehabil 71: 140-144. [Crossref]
27. Kendall E, Terry D (2009) Predicting emotional well-being following traumatic brain injury: a test of mediated and moderated models. Social Sci Med 69: 947-54.

Copyright: $(\mathrm{O} 2016$ Bulsara CE. This is an open-access article distributed under the terms of the Creative Commons Attribution License, which permits unrestricted use, distribution, and reproduction in any medium, provided the original author and source are credited. 